\title{
Investigation of the relationship between structural empowerment and organizational commitment of nurses in Zanjan hospitals.
}

Fereidoun Eskandari ${ }^{1}$, Soheila Rabie Siahkali ${ }^{2}$, Alireza Shoghli ${ }^{3}$, Mehrnoosh Pazargadi $^{4}$, Mansoreh Zaghari Tafreshi ${ }^{5}$

1. Department of Nursing Management, Mousavi Teaching Hospital, ZanjanUniversity of Medical Sciences, Zanjan, Iran

2. Department of Nursing, School of Nursing and Midwifery, Zanjan University of Medical Sciences, Zanjan, Iran

3. Department of Health Management, School of Medicine, Zanjan University of Medical Sciences, Zanjan, Iran

4. Department of Management, School of Nursing and Midwifery, Shahid Beheshti University of Medical Sciences, Tehran, Iran

5. Department of School of Nursing, School of Nursing and Midwifery, Shahid Beheshti University of Medical Sciences, Tehran, Iran

\begin{abstract}
Background: The demanding nature of nursing work environments signals longstanding and growing concerns about nurses' health and job satisfaction and the provision of quality care. Specifically in health care settings, nurse leaders play an essential role in creating supportive work environments to avert these negative trends and increase nurse job satisfaction.

Objective: The purpose of this study was to examine the relationship between structural empowerment and organizational commitment of nurses.

Methods: 491 nurses working in Zanjan hospitals participated in this descriptive-correlational study in 2010. Tools for data collection were Meyer and Allen's organizational commitment questionnaire and "Conditions for Work Effectiveness Questionnaire-II" (CWEQ-II). Data was analyzed by SPSS16. The statistical tests such as variance analysis, t-test, pearson correlation coefficient and linear regression were used for data analysis.

Results: According to the findings, the perception of nurses working in hospitals on "Structural Empowerment" was moderate (15.98 \pm 3.29$)$. Nurses believed "opportunity" as the most important element in structural empowerment with the score of 3.18 土0.79. Nurses working in non-academic hospitals and in non-teaching hospitals had higher organizational commitment than others. There was a significant relationship between structural empowerment and organizational commitment.

Conclusion: Generally, structural empowerment (relatively strong) correlates with nurses' organizational commitment. We concluded that a high structural empowerment increases the organizational commitment of nurses.
\end{abstract}

Keywords: Structural empowerment, organizational commitment, nurses, Zanjan.

DOI: https://dx.doi.org/10.4314/ahs.v17i1.35

Cite as: Eskandari F, Siahkali SR, Shoghli A, Pazargadi M, Tafreshi MZ. Investigation of the relationship between structural empowerment and organizational commitment of nurses in Zanjan hospitals. Afri Health Sci. 2017;17(1): 285-292. https:/ / dx.doi.org/10.4314/abs.v17i1.35

\section{Introduction}

Nurses constitute the largest group of health care providers and their professional capability plays an important role in fulfilling the health system. That's why their professional and caring capability is one of the concerns of the

\section{Corresponding author:}

Soheila Rabie Siahkali,

Department of Nursing,

School of Nursing and Midwifery,

Zanjan University of Medical Sciences, Zanjan, Iran

Tel :+989123416782

Email: rabie2@zums.ac.ir health care system and authorities in different countries. Nurses require power to affect patients, physicians and other health care practitioners ${ }^{1-5}$. Powerless nurses are ineffective nurses and they are less satisfied with their jobs ${ }^{6}$ and also prone to exhaustion and depersonalization ${ }^{7}$.

The lack of nursing power may be also found in patients outcomes. Some studies suggest that there are compelling reasons for empowerment in nursing ${ }^{6}$. Empowerment for nurses may consist of three components: a workplace that has the requisite structures to promote empowerment; a psychological belief in one's ability to be empowered; and acknowledgement that there is power in the relationships and care that nurses provide. A more 
thorough understanding of these three components may help nurses to become empowered and use their power for better patient care ${ }^{6}$. According to Kanter, structural empowerment means strengthening the structures in delegating independent authority, vote, responsibility and decision making opportunities to employees. ${ }^{5}$ Restricting the participation of nurses in decision-making causes their inefficiency and risk to patient safety ${ }^{8}$. Organizational commitment is a kind of attitude indicating the amount of staff interest and devotion and loyalty to the organization and their willingness to remain in an organization. This attitude includes three dimensions: affective commitment, continued commitment and normative or task commitment ${ }^{9}$.

Numerous studies have shown that in general, structural empowerment has a relatively strong correlation with nurses' organizational commitment. In the study of Desico et al., ${ }^{10}$ structural empowerment had a strong correlation with nurses' organizational commitment. On the other hand, Gholami et al., ${ }^{11}$ showed that there is a significant relationship between empowerment and organizational commitment ${ }^{11}$. And in another study by Wagner et al., ${ }^{12}$ it was shown that spiritual connection had a causal effect on organizational commitment, while resonant leadership and individual empowerment had significant causal influence on SAW (the spirit at work), job satisfaction, and organizational commitment. These results strengthen those of previous studies reporting work place structures/processes/contributions leading to superior care environments ${ }^{12}$.

Modifying the work place structure and improving nurses access to opportunities (organizational support, information and resources) and power (resources needed for development, opportunities to increase employees' competence, skills, reward and appreciation for skills and expertise) by nursing managers can increase the different outcomes of nursing practice including organizational commitment. ${ }^{13-16}$ Employees with high organizational commitment show more flexibility with organizational changes and higher job satisfaction, due to more trust in the organization's goals and values ${ }^{17}$. But those who are less committed have more absence at work ${ }^{18,19}$. With regard to the importance of nurses' commitment and its role on patient care outcomes, this study was designed to investigate the association between structural empower- ment and organizational commitment of nurses in hospital.

\section{Materials and methods \\ Study population}

This study is a descriptive correlational survey. The study population was all nurses working in 10 hospitals of Zanjan province (except military hospital). All nurses eligible to participate in the study were selected as subjects. Census method was used to select the sample. Among 800 nurses working in hospitals, 583 were eligible and were included in the study. Study hospitals included 4 teaching hospitals and 4 non-teaching hospitals associated with University of Medical Sciences of Zanjan and 2 hospitals covered by Social Security Organization.

\section{Tools and questions to measure the nurses' percep- tions}

To collect data and measure the main variables in this study, a two-part questionnaire was used, consisting of reliable and valid tool. "Conditions for Work Effectiveness Questionnaire-II" (CWEQ-II) was used to measure the structural empowerment of nurses. This tool was developed by Laschinger in 1996 and its short form consisted of 19 questions to measure the nurses' perceptions in achieving six subgroups workplace empowerment structure, including "Opportunity" questions 1 to 3, "Access to Information" question 4 to 6, "Support" question 7 to 9, "Access to Resources" question 10 to 12, "Formal Power " question 13 to 15 and "Informal Power" question 16 to19. The questions were adjusted based on 5-point Likert scale from strongly disagree (score 1), disagree (score 2), indifferent (score 3), agree (score 4) and strongly agree (score 5), and participants showed their agreements with each of the items by selecting one of the 5 options. The score of each question ranged from 1 (lowest) to 5 (highest) and the mean score for each aspect was calculated from 1 to 5 .

The total score of structural empowerment was obtained by adding the mean of 6 aspects in the range of 6 to 30. Laschinger (2005) has classified empowerment scores into three levels of low (6 to 14), average (14.1 to 22) and high (22.1 to 30). This tool includes two other questions as overall empowerment measure and validation of participants' responses to 19 main items, that these questions are not counted in determining the score of nurses' empowerment. The correlation between the two questions 
of total empowerment with the main questions of structural empowerment was obtained equal to $(\mathrm{r}=0.78)$ using Spearman test, indicating the strong correlation between these two parts. This structural empowerment tool was translated by the researcher with permission of its creator which for the first time in this study was used for nursing environment in Iranian hospitals. The tool of "Conditions of Work Effectiveness" (CWEQ-II), first was translated and edited, then was presented to a number of academy staff and nurses to control of statements in terms of face validity, and the scoring of each question in terms of relevance, clarity and fluency (content validity). After revision of the questionnaire, the content validity index(CVI) was calculated as equal to 0.89 for the whole tool while its minimum and maximum were obtained 0.80 for question 5 (opportunity dimension) and 0.97 for question 8 (support dimension), respectively.

\section{The score of each question}

Meyer and Allen's organizational commitment questionnaire ${ }^{11}$ was used to measure organizational commitment, consisting of 24 questions in three aspects of affective commitment (question 1 to 8), continuous commitment (question 9 and 16) and normative or task commitment (question 17 to 24). The questions were adjusted based on the 5-point Likert scale from not at all (score 1), a little (score 2), somewhat (score 3), much (score 4) and very much (score 5), and participants showed their agreements with each of the items by selecting one of the 5 options. The score of each question ranged from 1 (lowest) to 5 (highest), the mean score for each aspect was calculated from 1 to 5 and the total score of organizational commitment was determined (3 to 15). Higher scores indicate higher levels of organizational commitment. The tool has been repeatedly used in Iran and even in studies on nursing ${ }^{4}$.

\section{Results}

$90 \%$ (445) of participants in this study were female. The mean age of participants was $30.72 \pm 4.65 .72 .1 \%$ (354) of participants were married and the rest were single. $72.5 \%$ (361) of nurses were in the range of 25 to 34 years. Most nurses had less than 11 years of working experience $(83.1 \%)$ and $69.7 \%$ of them had less than 6 years of working experience in the hospital. $43.4 \%$ of the nurses working in the hospital were in unsustainable condition and the majority (57.8\%) reported that their hospital's salary was not enough. The majority of nurses $(71.5 \%)$ were working in 4 teaching hospitals and $85.3 \%$ were employed in University hospitals. Structural empowerment of nurses with an average score of $15.87 \pm 3.29$ was at moderate level and among the dimensions of structural empowerment, the opportunity dimension and formal power dimension had the highest and lowest score, respectively. Male nurses with a total score of $16.71( \pm 3.45)$ and $(p=0.05)$ and the participants aged over 40 years with a total score of $17.97( \pm 4.51)$ and $(p=0.007)$ had more positive perception of the structural empowerment than others and this difference was statistically significant. The nurses working in non-teaching hospitals had higher perception of the structural empowerment than others with score of $16.44( \pm 3.2)$ and $(p=0.02)$, the difference was also statistically significant. The nurses in emergency departments with a total score of $16.41( \pm 3.62)$ and $(p=0.009)$ had higher perception of the structural empowerment than others and it was statistically significant. The results showed that with increasing job experience over 20 years, structural empowerment increases significantly with a mean of $19.08( \pm 3.00)$ and $(p=0.01)$. Nurses who thought their received salary was enough had higher understanding of structural empowerment with score of 16.95 (3.97) than the others, and this difference was statistically significant $(\mathrm{P}<0.001)$.

The average score of nurses' organizational commitment with the mean of $9.59( \pm 2.07)$ was at average level and the continued commitment with a score of $3.22( \pm 0.74)$ was the dominant commitment. Short term contract nurses with the mean score of $9.28( \pm 1.98)$ and $(p=0.01)$, had less organizational commitment than others, which the difference was statistically significant. Nurses working in non-academic hospitals with the score of $10.25( \pm 2.12)$ and $(p=0.003)$ and in non-teaching hospitals with scores of $9.90( \pm 2.15)$ and $(p=0.03)$ had higher organizational commitment than others, and the difference was statistically significant. Only working in the hospital nurses, with the score of $9.68( \pm 2.01)$ and $(p=0.006)$ and nurses who thought their received salaries were quite enough with the score of $10.18( \pm 1.91)$ and $(\mathrm{P}<0.001)$ had higher organizational commitment than others, and the difference was statistically significant.

The ANOVA tests revealed that there were statistically significant differences among the grades and dimensions of organizational commitment. Tukey test for pairwise comparisons showed statistically significant differences 
$(\mathrm{p}<0.001)$ between the scores of organizational commitment, affective commitment, continuance commitment and task commitment in the groups. As seen in the table 1, with increasing structural empowerment scores from low group to top group, their organizational commitment

Table 1: The mean score of organizational commitment and its dimensions in three groups of the structural empowerment of nurses.

\begin{tabular}{|c|c|c|c|c|c|c|c|}
\hline $\begin{array}{l}\text { The mean sc } \\
\text { Structural Empor }\end{array}$ & ore of or & $\begin{array}{l}\text { zational } \\
\text { nitment }\end{array}$ & & Affective & Continued & Task & $\begin{array}{c}\text { Total } \\
\text { organization }\end{array}$ \\
\hline $\begin{array}{l}\text { Grouping } \\
\text { structural } \\
\text { empowerment }\end{array}$ & Count & $\begin{array}{l}\text { Percen } \\
\mathrm{t}\end{array}$ & $\begin{array}{l}\text { The mean } \\
(\mathrm{SD})\end{array}$ & nt (SD ) & (SD) & (SD ) & $\begin{array}{c}\text { commitment } \\
\text { (SD ) }\end{array}$ \\
\hline Low (6-14) & 145 & 29.5 & $12.41(1.61)$ & $2.75(0.97)$ & $2.99(0.79)$ & $2.82(0.83)$ & $8.56(2.07)$ \\
\hline $\begin{array}{c}\text { Medium (14.01- } \\
22)\end{array}$ & 327 & 67.0 & $17.11(2.03)$ & $3.31(0.75)$ & $3.28(0.69)$ & $3.32(0.76)$ & $9.91(1.85)$ \\
\hline $\operatorname{High}(22.01-30)$ & 17 & 3.5 & $23.68(1.40)$ & $4.15(0.77)$ & 4.01(0.69) & $3.89(0.92)$ & $12.05(2.39)$ \\
\hline Total & 491 & 100 & $15.87(3.30)$ & $3.17(0.88)$ & $3.22(0.74)$ & $3.19(0.83)$ & $9.59(2.07)$ \\
\hline $\mathrm{P}$-value test & & & & $\begin{array}{l}\text { ANOVA } \\
\mathrm{P}<0.001\end{array}$ & $\begin{array}{l}\text { ANOVA } \\
\mathrm{P}<0.001\end{array}$ & $\begin{array}{l}\text { ANOVA } \\
\mathrm{P}<0.001\end{array}$ & $\begin{array}{l}\text { ANOVA } \\
\mathrm{P}<0.001\end{array}$ \\
\hline
\end{tabular}

scores also increase and this increase was statistically significant (Table 1).

Pairwise comparison of the groups in each dimension of the structural empowerment revealed that there was a statistically significant difference in the total organizational commitment and all its dimensions, between the scores of the bottom group for dimension opportunity with the other two groups. In the dimension of access to information, there were differences in the scores of overall organizational commitment among all groups. With regard to the support dimension, there were statistically significant differences between the affective commitment and the task commitment of bottom group and moderate and high groups. Based on both dimensions of access to resources and formal power, there were statistically signif- icant differences between the affective, continuous, task and total organizational commitments of bottom group with the two other groups. With regard to informal power, there was also a statistically significant difference in the scores of organizational commitment and affective commitment among all groups.

The total structural empowerment had relatively strong correlation with organizational commitment of nurses $(r=0.444)$. Among the dimensions, most of all, the "formal power" had higher correlation with the organizational commitment $(r=0.372)$ and after which the "Access to Information" was more correlated $(\mathrm{r}=0.361)$. The lowest correlation was between the dimension of the "opportunity" with the organizational commitment of nurses $(r=0.161)$. All dimensions of structural empowerment had higher correlation with task commitments compared 
Table 2: correlation between dimensions and total score of structural empowerment with dimensions and total score of organizational commitment of nurses

\begin{tabular}{|c|c|c|c|c|c|}
\hline Structural & & Pearson's corn & lation coeffici & & \\
\hline Dimensions & $\begin{array}{l}\text { Average } \\
\text { (Standard } \\
\text { deviation) }\end{array}$ & $\begin{array}{l}\text { Affective } \\
\text { commitment }\end{array}$ & $\begin{array}{l}\text { Continued } \\
\text { commitment }\end{array}$ & $\begin{array}{l}\text { Task } \\
\text { commitment }\end{array}$ & Total \\
\hline opportunity & $3.19(0.80)$ & $\begin{array}{l}\mathrm{r}=0.136 \\
\mathrm{P}=0.003\end{array}$ & $\begin{array}{l}r=0.129 \\
P=0.004\end{array}$ & $\begin{array}{l}\mathbf{r}=\mathbf{0 . 1 4 1} \\
\mathrm{P}=0.002\end{array}$ & $\begin{array}{l}\mathbf{r}=\mathbf{0 . 1 6 1} \\
\mathrm{p}<0.001\end{array}$ \\
\hline access to information & $2.39(0.83)$ & $\begin{array}{l}r=0.204 \\
p<0.001\end{array}$ & $\begin{array}{l}\mathrm{r}=0.333 \\
\mathrm{p}<0.001\end{array}$ & $\begin{array}{l}r=0.363 \\
p<0.001\end{array}$ & $\begin{array}{l}\mathbf{r}=\mathbf{0 . 3 6 1} \\
\mathrm{p}<0.001\end{array}$ \\
\hline support & $2.54(0.85)$ & $\begin{array}{l}r=0.196 \\
p<0.001\end{array}$ & $\begin{array}{l}\mathrm{r}=0.346 \\
\mathrm{p}<0.001\end{array}$ & $\begin{array}{l}r=0.365 \\
p<0.001\end{array}$ & $\begin{array}{l}r=0.359 \\
p<0.001\end{array}$ \\
\hline access to resources & $2.73(0.69)$ & $\begin{array}{l}r=0.171 \\
p<0.001\end{array}$ & $\begin{array}{l}\mathrm{r}=0.212 \\
\mathrm{p}<0.001\end{array}$ & $\begin{array}{l}\mathrm{r}=0.290 \\
\mathrm{p}<0.001\end{array}$ & $\begin{array}{l}r=0.271 \\
p<0.001\end{array}$ \\
\hline formal power & $2.18(0.80)$ & $\begin{array}{l}r=0.221 \\
p<0.001\end{array}$ & $\begin{array}{l}r=0.307 \\
p<0.001\end{array}$ & $\begin{array}{l}\mathbf{r}=\mathbf{0 . 3 9 5} \\
\mathbf{p}<0.001\end{array}$ & $\begin{array}{l}r=0.372 \\
p<0.001\end{array}$ \\
\hline informal power & $2.83(0.72)$ & $\begin{array}{l}\mathbf{r}=\mathbf{0 . 2 5 8} \\
\mathrm{p}<0.001\end{array}$ & $\begin{array}{l}r=0.269 \\
p<0.001\end{array}$ & $\begin{array}{l}r=0.314 \\
p<0.001\end{array}$ & $\begin{array}{l}r=0.335 \\
p<0.001\end{array}$ \\
\hline $\begin{array}{l}\text { Total Structural } \\
\text { Empowerment }\end{array}$ & (3.30)15.87 & $\begin{aligned} r & =0.281 \\
p & <0.001\end{aligned}$ & $\begin{aligned} r & =0.382 \\
p & <0.001\end{aligned}$ & $\begin{aligned} r & =0.443 \\
p & <0.001\end{aligned}$ & $\begin{array}{l}r=0.444 \\
p<0.001\end{array}$ \\
\hline
\end{tabular}

to the two other types of affective commitment and continuance commitment (Table 2).
Linear regression analysis results showed that nurses with high experience in University hospitals may be a better

Table 3: The relationship between structural empowerment and organizational commitment of nurses based on demographic variables

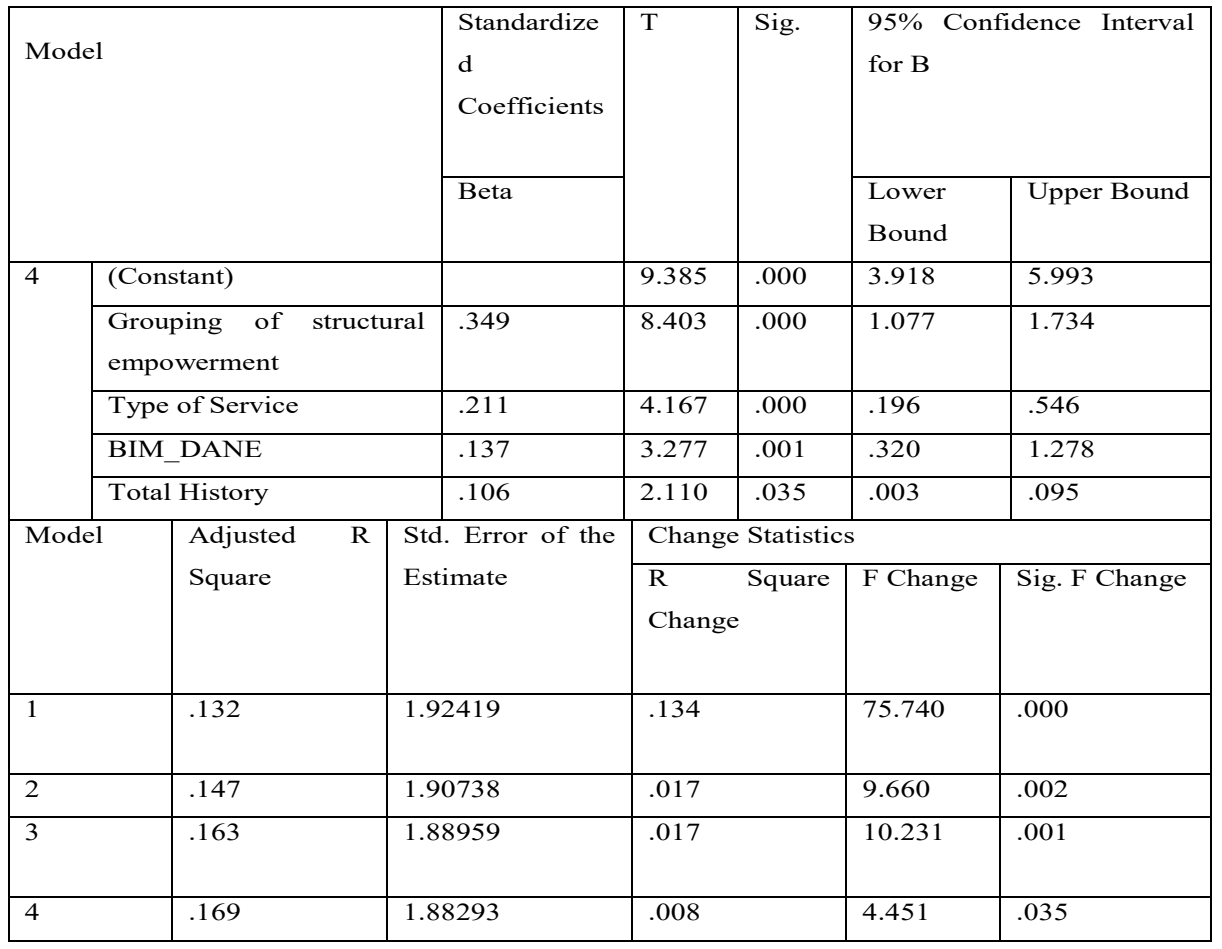

predictor of organizational commitment and empowerment in results of an organizational structure (Table 3).

\section{Discussion}

According to the Findings, hospital-working nurses' perception of "structural empowerment" was moderate 15.87 (3.29). In concordance with our study, the effect of structural empowerment and the organizational commitment on Chinese nurses' job satisfaction by Jinhua
Yang et al. showed moderate level of empowerment ${ }^{20}$. The nurses knew "opportunity" as the most important element in the structural empowerment with the score of $3.18(0.79)$ and "Informal Power" as the second with the mean score of 2.82 (0.72). In contrast,"Formal Power" obtained the lowest score of structural empowerment $(2.18 \pm 0.80)$. The result is inconsistent with the finding of Laschinger et al. ${ }^{18}$ and Faulkner et al. ${ }^{17}$ Structural empow- 
erment understanding for nurses with an average age of 42 years old and 17 year experience was equal to 19.44 (1.14) in the study of Laschinger et al. ${ }^{21}$. However, the general understanding of structural empowerment for nurses was 12.95 (3.14) in other study of Laschinger and Patrick ${ }^{13}$. In the study of DeCicco et $\mathrm{al}^{10}$ conducted in a nursing home, the average scores of nurses' and auxiliary nurses' empowerment were 19.42 (4.44) and 17.69 (3.85), respectively, that is more than the empowerment of nurses working in hospitals and it could be due to a higher authority delegated to nurses in mentioned centers. In the study of Donahue et al..$^{22}$ carried out on 259 recruited nurses to determine the relationship between nurses' perceptions of empowerment and patient satisfaction in Greenwich Ohio Hospital, the mean score of nurses' structural empowerment was above average (21.28).

Male nurses had a high score of $16.71 \pm 3.45$ in the perception of structural empowerment. In the informal power dimension, male nurses with a mean of 3.05 $(0 / 76)$ had higher score than others, this difference was statistically significant. According to Raphael ${ }^{23}$ the power as a result of being male is considered directly in front of the point of care, which is known as nursing extract and orientated traditionally with being female. Most nurses (female) may be reluctant to access and use the power, because they know the power is masculine trait and consider it inconsistent with their character as a woman. Therefore, a male point of view of power may contribute to extend nurses' weakness. Manojlovich ${ }^{6}$ suggests that nurses may be more reluctant to describe power compared to most people, since $95 \%$ of nurses are women who are not socially acceptable to exercise the power. In the present study, $90.6 \%$ of nurses were female.

Nurses aged over 35 years with the score of 17.97 (4.51) and nurses in pediatric and neonatal units with the score of 16.41 (3.28) had higher structural empowerment than others that was statistically significant. With the increase of total work history, the scores of the perception of empowerment in "formal power dimension" increased, so that the nurses with more than 20 years experience had the mean score of 2.90 (0.76). The more experience one had led to significantly more score of nurses' understanding of structural empowerment, so that nurses with over 21 years experience possessed a high structural empowerment score (19.08 \pm 3.0$)$. Nurses working in one hospital had higher understanding of structural empowerment with a score of 17.4 (2.6) than the others, and this difference was statistically significant. It was determined in the mean of variables that a high structural empowerment score in the hospital is more related to the two aspects of "Formal Power" and "Informal Power". This result may be due to being non-teaching hospital and in an ethnic area. In the aspect of "Access to Resources", nurses working in intensive care units with an average of $2.80(0.62)$ and emergency department with an average of $2.81(0.76)$ had higher scores than others, that the difference was statistically significant. These findings were higher in male nurses and age groups above 35 years old, than the other groups. These results are inconsistent with the findings of Laschinger and Patrick ${ }^{3}$. In Faulkner and Laschinger study ${ }^{17}$, no significant relationship was found between individual variables such as age, sex, education level, employment status, type of hospital and nursing experience with structural empowerment. Peachey ${ }^{24}$ also concluded that older nurses access more opportunities, resources and organizational information and coordinate their tasks to organizational goals. McMahon ${ }^{25}$ stated that the nurses learn in most of the time to take action in the range of operational structures and organizational work. Moreover, they feel empowered when they are closer to the goals of their work unit. ${ }^{24}$

Nurses working in non-academic hospitals had higher understanding of structural empowerment with score of 16.44 (3.2) than the others, and this difference was statistically significant. Low score of structural empowerment in University hospitals could be due to the multiplicity of educational groups in the hospital and the presence of certain limitations for nurses on the exercise of power. In our study, the total structural empowerment had relatively strong correlation with organizational commitment of nurses $(r=0.444)$. This result was in agreement with Ibraham et al. study entitled "work place empowerment and organizational commitment of nurses at the Egypt University Hospital", which showed a significant direct intermediate correlation between nurses' perceptions of overall structural empowerment and their overall organizational commitment ${ }^{26}$. In this study, overall structural empowerment with the working department $(\mathrm{P}=0.031)$, and overall organizational commitment with nursing experience $(\mathrm{P}=0.025)$ was significant. The results of Yang et al.'s study among nurses supported the results in the 
relationship between empowerment and organizational commitment ${ }^{20}$.

In our study, the high correlation of "informal power" with "Structural Empowerment" is in consistent with the findings of Manojlovich ${ }^{27}$ which refers that the nurses with high perception in the structural empowerment have more effective communications with doctors. The low mean age of samples and low experience in hospitals and wards can be the reasons for the low score of structural empowerment in our study. The results of the findings in "Opportunity" were inconsistent with the findings of Laschinger and Hatcher ${ }^{2}$, and Decicco et al., ${ }^{10}$ but the dimension of "Access to Resources" had the lowest score in these studies.

The results of Ahmad et al. study in Malaysia and England showed that although the Malaysian nurses felt more empowered and committed to their organization, the English nurses were more satisfied with their jobs. ${ }^{28}$ The differences between these two groups of nurses show that empowerment does not generate the same results in all countries, and reflects empirical evidence from most cross cultural studies on empowerment .

Support for an expanded model of Kanter's structural empowerment was achieved in our study. Hospital administrators are recommended to improve conditions, working environment, and nurses' salary to increase structural empowerment, organizational commitment, leading to better service to our patients by nurses and to increase satisfaction.

\section{Conclusion}

Generally, the structural empowerment and the organizational commitment of nurses are relatively strongly correlated with each other. Low empowerment groups had a high organizational commitment score in most aspects. It means that a low structural empowerment does not necessarily lead to lower organizational commitment, but a high structural empowerment increases the organizational commitment of nurses. These findings are consistent with findings from previous studies, and there is a significant relationship between structural empowerment and organizational commitment.

\section{Acknowledgments}

We appreciate all respected staff and nurses in health service centers and this study was supported by Zanjan University of Medical Sciences.

\section{Conflict of interest}

We certify that there is no conflict of interest with any financial organization regarding the material discussed in this article.

\section{References}

1. Manojlovich M, Laschinger HKS.The relationship of empowerment and selected personality characteristics to nursing job satisfaction. Journal of Nursing Administration 2002; 32 (11):586-595

2. Laschinger HKS. A theoretical approach to studying work empowerment in nursing: a review of studies testing Kanter's theory of structural power in organizations. Nursing administration quarterly 1996;20 (2):25-41

3. Patrick A, Laschinger HKS.The effect of structural empowerment and perceived organizational support on middle level nurse managers' role satisfaction. Journal of nursing management 2006;14 (1):13-22

4. Yaghoubi M, Raeisi AR, Afshar M. The relationship between learning organization and organizational commitment among nursing managers in educational hospitals of Isfahan University of Medical Sciences in 20089. Iranian Journal of nursing and midwifery research 2010;15 (2):83

5. KanterRM. Men and Women of the Corporation, vol 5049. Basic books, 1977

6. Manojlovich M.Power and empowerment in nursing: Looking backward to inform the future. Online Journal of Issues in Nursing 2007;12 (1)

7. Leiter MP, Laschinger HKS.Relationships of work and practice environment to professional burnout: testing a causal model. Nursing Research 2006;55 (2):137-146. PubMed

8. Baumann A, Giovannetti P, O'Brien-Pallas L, Mallette C. Healthcare restructuring: the impact of job change. Canadian Journal of Nursing Leadership 2000;14 (1):14-20

9. Meyer JP, Allen NJ.A three-component conceptualization of organizational commitment. Human resource management review 1991;1 (1):61-89

10. DeCicco J, Laschinger H, Kerr M.Perceptions of empowerment and respect: effect on nurses' organizational commitment in nursing homes. Journal of Gerontological Nursing 2006;32 (5):49-56

11. Gholami Z, Soltanahmadi JA, Pashavi G, Nekouei S.Empowerment as a Basic Step in Upgrading Organizational Commitment and Organizational Citizenship Behaviors: A Case Study on Public Sector in Iran. World Applied Sciences Journal 2013;21 (11):1693-1698

12. Wagner J, Cummings G, Smith D, Olson J, Warren S.Resonant Leadership, workplace empowerment and spirit at work: Impact on job satisfaction and organizational commitment for Registered Nurses. Canadian Jour- 
nal of Nursing Research 2013;45:1-16

13. Laschinger HKS, Finegan J, Shamian J.Promoting nurses' health: Effect of empowerment on job strain and work satisfaction. Nursing Economics 2001;19 (2):42 PubMed

14. Wilson B, Laschinger HKS.Staff Nurse Perception of Job Empowerment and Organizational Commitment: A Test of Ranter's Theory of Structural Power in Organizations. Journal of Nursing Administration 1994;24 (4S):39-47 15. Organization WH.Strategic directions for strengthening nursing and midwifery services. World Health Organization, 2002

16. Yang F-H, Chang C-C.Emotional labour, job satisfaction and organizational commitment amongst clinical nurses: A questionnaire survey. International Journal of Nursing Studies 2008;45 (6):879-887

17. Faulkner J, Laschinger H.The effects of structural and psychological empowerment on perceived respect in acute care nurses. Journal of nursing management 2008;16 (2):214-221

18. LaschingerHKS, Finegan J, Shamian J.The impact of workplace empowerment, organizational trust on staff nurses' work satisfaction and organizational commitment. Health care management review 2001;26 (3):7-23

19. Eskandari F, Pazargadi M, Zagheri Tafreshi M, Rabie Siahkali S, Shoghli AR. Relationship between Psychological Empowerment with Affective Commitment among Nurses in Zanjan, 2010. Preventive Care in Nursing \& Midwifery Journal 3 2014;(2):47-60

20. Yang J, Liu Y, Huang C, Zhu L. Impact of empowerment on professional practice environments and or- ganizational commitment among nurses: A structural equation approach. International Journal of nursing practice 2013;19 (S1):44-55

21. Laschinger HKS, Leiter M, Day A, Gilin D.Workplace empowerment, incivility, and burnout: Impact on staff nurse recruitment and retention outcomes. Journal of nursing management 2009;17 (3):302-311

22. Donahue MO, Piazza IM, Griffin MQ, Dykes PC, Fitzpatrick JJ.The relationship between nurses' perceptions of empowerment and patient satisfaction. Applied Nursing Research 2008;21 (1):2-7

23. Raphael ARF.Power and caring: a dialectic in nursing. Advances in Nursing Science 1996;19 (1):3-17

24. Peachey GA. The effect of leader empowering behaviours on staff nurses workplace empowerment, psychological empowerment, organizational commitment, and absenteeism. McMaster University, 2002

25. McMahon R, Pearson A. Nursing as therapy. Nelson Thornes, 1998

26. Ibrahem SZ, Elhoseeny T, Mahmoud RA.Workplace empowerment and organizational commitment among nurses working at the Main University Hospital, Alexandria, Egypt. The Journal of The Egyptian Public Health Association 2013;88 (2):90-96

27. Manojlovich M.Linking the Practice Environment to Nurses' Job Satisfaction Through Nurse-Physician Communication. Journal of Nursing Scholarship 2005;37 (4):367373

28. Ahmad N, Oranye NO. Empowerment, job satisfaction and organizational commitment: a comparative analysis of nurses working in Malaysia and England. Journal of nursing management 2010;18 (5):582-591 